\title{
ABSORÇÃO DE NUTRIENTES PELO ARROZ EM RESPOSTA À CALAGEM E À ÉPOCA DE INÍCIO DE IRRIGAÇÃO ${ }^{1}$
}

\author{
NUTRIENT UPTAKE BY RICE IN RESPONSE TO LIME AND TIME OF FLOODING
}

\author{
Angélica Polenz Wielewicki ${ }^{2}$ Enio Marchezan ${ }^{3}$ Lindolfo Storck $^{3}$
}

\section{RESUMO}

Este trabalho foi desenvolvido com o objetivo de avaliar a influéncia da correção da acidez do solo e da época de inicio de irrigação na absorção de nutrientes pelas plantas de arroz irrigado. Foram conduzidos dois experimentos, um para cada época de inicio de irrigação aos 15 e aos 35 dias após a emergència das plantulas, na área experimental do Departamento de Fitotecnia da UFSW em solo planossolo, sob delineamento de biocos ao acaso com quatro repetiçôes. Os tratamentos em cada experimento foram os seguintes: (1) sem calcário: (2) $300 \mathrm{~kg} / \mathrm{ha}$ de calcário classe D. um dia antes da semeadura: (3) 1.6t/ha de calcario classe C. um dia antes da semeadura: (4) 1,6t/ha de calcário classe C. 30 dias antes da semeadura: (5) 3,2t/ha de calcário classe (C. um dia antes da semeadura: e. (6) 3,2t/ha de calcário classe (. 30 dias antes da semeadura. A antecipação da época de inicio de irrigação proporciona maior absorção de mutrientes e maior produção de massa seca na parte aérea das plantas de arroz. e entretanto, a adição de calcário não aumenta absorção de nutrientes pela plantas de arroz e também não aumenta a produção de massa seca.

Palavras-chave: Oryza sativa L., massa seca. calcário.

\section{SI MMARY}

The objective of this paper was to evaluate the influence of acidity correction and the time of flooding in nutrient uptake by flooded rice crop. Two experiments were conducted at the experimental field of the Department of Phytotechny of the Federal University of Santa Maria (UFSM), with two different

\begin{abstract}
times of flooding, 15 and 35 days after emergence, in an Albaquaf soil. The experiment was a completely randomized block design with four replication. The treatments in each experiment were the following: (I) no lime: (2) $300 \mathrm{~kg} / \mathrm{ha}$ of class D lime, one day before seeding; (3) 1.6t/ha of class C lime, one day before seeding; (7) 1.6t/ha of class C lime, 30 days before seeding; (5) 3.2t/ha of class Clime, one day before seeding: and. (6) $3.2 \mathrm{t} / \mathrm{ha}$ of class Clime, 30 days before seeding. The antecipation of flooding increases the production of shoot dry matter and the absorption of nutrients by rice plants. However liming does not increase mutrient uptake and rice dry matter.
\end{abstract}

Key words: Oryza sativa $L$., lime, dry matter.

\section{INTRODUÇÃO}

O suprimento de nutrientes pelo solo às plantas é influenciado negativamente pela acidez do solo. Entretanto, é comum em solos ácidos a ocorrência de problemas de disponibilidade ou desbalanço de nutrientes, que provocam desordens nutricionais de complexidade e intensidade diversas, refletindo-se sobre o desenvolvimento e a produtividade das plantas (KAMINSKI, 1989). Os principais problemas da acidez do solo estão relacionados com a toxidez de $\mathrm{Al}^{+++}$e $\mathrm{Mn}$, que é mais severa até $\mathrm{pH}$ 5,0 e praticamente nula a partir de $\mathrm{pH} 5,5$ (FOY,1974).

\footnotetext{
${ }^{1}$ Parte da dissertação de Mestrado do primeiro autor, apresentada ao Curso de Pós-graduação em Agronomia da Universidade Federal de Santa Maria (UFSM).

${ }^{2}$ Engenheiro Agrònomo, Mestre, Bolsista da CAPES.

${ }^{3}$ Engenheiro Agrônomo. Doutor, Prolessor Titular, Departamento de Fitotecnia, Centro de Ciências Rurais, UFSM, 97119-900, Santa Maria. RS. Bolsista CNPq. Autor para correspondencia. E-mail: emarch $a$ ccr.ufsm.br 
A submersão dos solos provoca uma série de processos físicos, químicos e biológicos que influenciam a capacidade do solo em atuar como meio para o crescimento das plantas. Assim, embora a literatura na área pareça convergir no sentido de que tal influência é benéfica, há alguma divergência no que concerne à época mais apropriada para início da irrigação definitiva, dependendo dos parâmetros considerados (GOMES et al., 1981 e GOMES et al., 1987). Dessa forma, se por um lado, a antecipação da época de início de irrigação favorece a correção do nível de saturação da capacidade de troca de cátions do solo por $\mathrm{Al}^{++}$(LOPES, 1996), por outro lado, tal prática aumenta os custos da irrigação da lavoura de arroz (GOMES et al., 1987). Há, portanto, que se postular estudos que considerem a questão da época de início de irrigação definitiva, observando tanto suas influências benéficas para a cultura do arroz (correção de acidez e o aumento da disponibilidade de P), quanto suas eventuais influências negativas (aumento na concentração de $\mathrm{Fe}^{++}$e $\mathrm{Mn}^{++}$, reportada por LEFROY et al., 1993).

Para que sejam dadas condições ideais para o desenvolvimento das plantas de arroz, a acidez do solo já deveria estar corrigida no início do desenvolvimento das plantas, quando estas são mais sensiveis aos fatores da acidez do solo, entre eles o $\mathrm{Al}^{+++}$(FOY, 1974). Neste sentido, a calagem de solos ácidos que serão cultivados com arroz irrigado, propiciaria às plântulas melhores condições para o seu desenvolvimento neste período inicial de seu ciclo, quando o potencial de rendimento de grãos da cultura é estabelecido.

O presente trabalho têm como objetivo relacionar os efeitos da calagem e de duas épocas de início de irrigação sobre a produção de massa seca da parte aérea e a absorção de nutrientes pelas plantas de arroz.

\section{MATERIAIS E MÉTODOS}

O trabalho foi desenvolvido no periodo de outubro de 1995 a abril de 1996, na área experimental do Departamento de Fitotecnia da Universidade Federal de Santa Maria, Rio Grande do Sul. O experimento foi conduzido em solo da unidade de mapeamento Vacacaí (Planossolo). Esses solos caracterizamse por possuírem textura média (15 a 35\% de argila), baixos a médios teores de matéria orgânica, pobres em nutrientes, mal drenados e fortemente ácidos, com pH em torno de 5,0.
Foram estabelecidas duas épocas para o início da irrigação. A primeira época foi aos 15 dias após a emergência das plântulas de arroz (DAE), constituindo o experimento I e a segunda época aos 35 DAE, como experimento II, permanecendo as áreas inundadas com lâmina d'água de $10 \mathrm{a} 15 \mathrm{~cm}$ de altura até o final do ciclo da cultura.

Em cada experimento foram testadas três diferentes doses de calcário, duas épocas de aplicação e duas granulometrias de calcário, sendo um calcário da classe C com PRNT $83 \%$ e outro da classe D com PRNT 91\%. Os tratamentos foram os seguintes: (1) tratamento sem calcário; (2) $300 \mathrm{~kg} / \mathrm{ha}$ de calcário classe D aplicados no dia anterior à semeadura; (3) 1,6t/ha de calcário classe C (50\% da recomendação) aplicados no dia anterior à semeadura; (4) 1,6t/ha de calcário classe C ( $50 \%$ da recomendação) aplicados 30 dias antes da semeadura; (5) 3,2t/ha de calcário classe $\mathrm{C}(100 \%$ da recomendação) aplicados no dia anterior à semeadura; e, (6) 3,2t/ha de calcário classe C (100\% da recomendação) aplicados 30 dias antes da semeadura. A recomendação adotada foi com base no índice SMP para atingir $\mathrm{pH} 5,5$.

A unidade experimental teve dimensões de $4 \times 6 \mathrm{~m}$ e os seis tratamentos foram distribuídos segundo o delineamento blocos ao acaso com quatro repetições, em cada um dos dois experimentos.

Antes da aplicação dos tratamentos, o calcário foi analisado em laboratório e foi realizada a correção do PRNT do produto para $100 \%$. O calcário foi distribuido nas doses definidas para cada tratamento, nas unidades experimentais e incorparado a uma profundidade de $10 \mathrm{~cm}$. A adubação de manutenção foi realizada no sulco de semeadura de acordo com a interpretação da análise química do solo (Tabela 1). A adubação utilizada foi de $200 \mathrm{~kg} / \mathrm{ha}$ da fórmula $02-20$ 20 aplicados na base e $75 \mathrm{~kg} / \mathrm{ha}$ da fórmula $45-00-00$ aplicados no início do primórdio floral (SBCS, 1995).

A semeadura foi realizada no dia 23 de novembro de 1995, utilizando a cultivar EMBRAPA 7 TAIM, distribuindo aproximadamente $180 \mathrm{~kg} / \mathrm{ha} \mathrm{de}$ sementes. A emergência das plântulas foi considerada completa em 06 de dezembro de 1995, após terem sido realizadas duas irrigações para uniformizar a emergência das plântulas. $O$ controle de invasoras foi realizado quimicamente, com $0,7 \mathrm{l} /$ ha de clomazone $+3 \mathrm{l} / \mathrm{ha}$ de propanil $450+0,1 \mathrm{l} /$ ha de $2,4-\mathrm{D}$, quando as plantas invasoras estavam com 2 a 3 folhas.

A irrigação no experimento I ( 15 DAE) foi iniciada no dia 21 de dezembro de 1995 e no experimento II (35 DAE) foi iniciada no dia 10 de janeiro de 1996. A precipitação pluvial entre o início de irrigação nos dois experimentos, ocorreu nos dias 24 a 27/12/95 e 05 a $06 / 01 / 96$ foi de $105,1 \mathrm{~mm}$. 
Tabela 1 - Resultado da análise do solo no qual foram desenvolvidos os dois experimentos, antes dos tratamentos com calcário. Santa Maria/RS, 1995.

\begin{tabular}{|c|c|}
\hline Variável & Valor \\
\hline 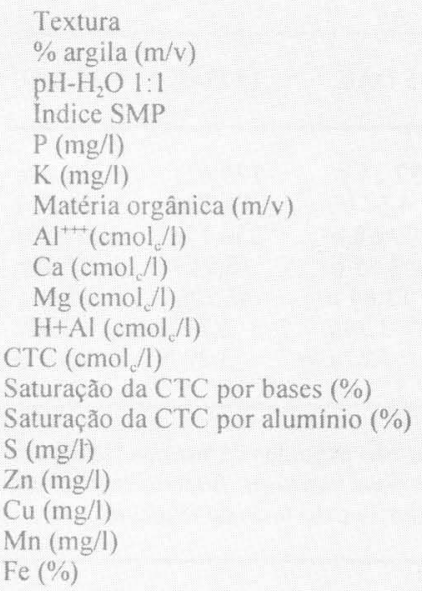 & $\begin{array}{r}4,0 \\
24,0 \\
4,7 \\
5,6 \\
5,0 \\
47,0 \\
2,6 \\
2,1 \\
4,7 \\
2,0 \\
8,8 \\
9,4 \\
47,0 \\
21,7 \\
31,5 \\
0,9 \\
1,3 \\
40,0 \\
0,45\end{array}$ \\
\hline
\end{tabular}

As determinações do acúmulo de nutrientes e da massa seca (MS) da parte aérea das plantas foram realizadas em três estádios de desenvolvimento da cultura (perfillhamento, floração e maturação) sendo que na maturação os grãos foram separados do restante da planta para análise. As amostras foram retiradas de secções de linha de $0,40 \times 0,15 \mathrm{~m}$ aleatoriamente localizadas e não desbastadas. As amostras foram levadas a estufa de ventilação forçada para secagem a temperatura de $70^{\circ} \mathrm{C}$ e a massa obtida foi convertida para $\mathrm{kg} / \mathrm{ha}$. As amostras de tecido de toda a parte área das plantas de arroz foram trituradas e a análise química de tecido foi determinada seguindo a metodologia descrita por TEDESCO et al. (1995).

Foi procedida a análise conjunta dos experimentos I e II para verificar a existência de interação entre épocas de início de irrigação e tratamentos com calcário. As variáveis avaliadas foram submetidas a análise de variância e as médias comparadas entre si pelo teste de Duncan em nível de 5\% de probabilidade.

\section{RESULTADOS E DISCUSSÃO}

A análise conjunta demonstrou que não houve interação entre os tratamentos com calcário e as épocas de início de irrigação para as variáveis massa seca e acúmulo de nutrientes nas avaliações realizadas nos estádios de perfilhamento, floração e maturação.
A produção de MS da parte área não diferiu significativamente entre os tratamentos com calcário, nas amostragens realizadas nos três estádios de desenvolvimento. FAGERIA et al. (1977) e PATRA \& MOHANTY (1994) também encontraram resultados semelhantes. Embora os autores não expliquem o efeito da calagem sobre a produção de MS, FAGERIA et al. (1977) cita que até o nível de $4,5 \mathrm{cmolc} / \mathrm{l}$ de $\mathrm{Al}^{+++}$, este elemento não causa problemas para a produção de massa seca em arroz irrigado, o que pode explicar os resultados obtidos, já que a concentração de $\mathrm{Al}^{+++}$no solo era de $2,1 \mathrm{cmolc} / \mathrm{l}$ (Tabela 1).

Quando se compara as épocas de início de irrigação, observa-se que a produção de MS da parte aérea foi maior no experimento I (15 DAE), para as coletas realizadas no perfilhamento e na maturação. No entanto, no estádio da floração não houve diferença estatística entre as épocas de início da irrigação (Figura 1), possivelmente devido a adubação de cobertura que foi realizada no início do primórdio floral e que promoveu um pico de crescimento das plantas, diminuindo a diferença existente na produção de MS entre as duas épocas de início de irrigação.

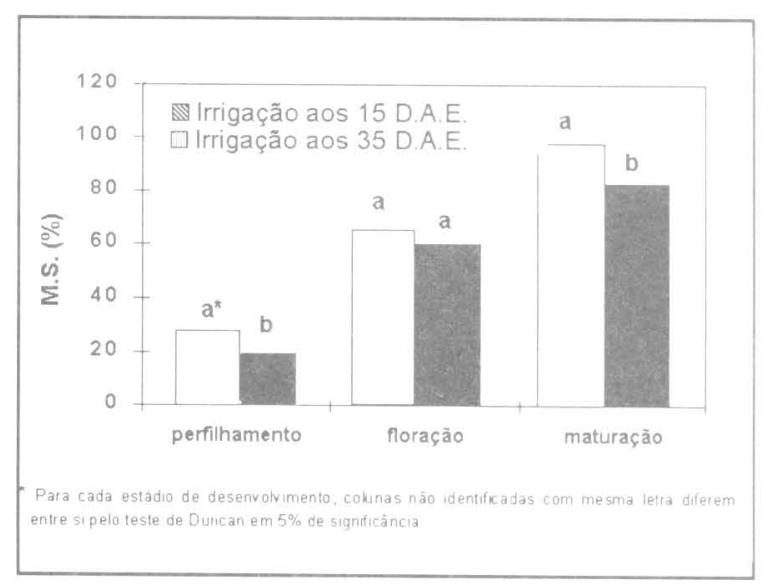

Figura 1 - Produção de massa seca da parte aérea das plantas de arroz sob duas épocas de início de irrigação nos estádios de perfilhamento, floração e maturação do arroz. Santa Maria/RS. 1995/96

Apesar da ocorrência de 105, $1 \mathrm{~mm}$ de precipitação pluvial no período entre os inícios de irrigação dos experimentos I e II, a irrigação antecipada do solo mostrou seus efeitos positivos sobre a produção de MS da parte aérea das plantas de arroz irrigado (Figura 1). Provavelmente, as melhores condições de desenvolvimento para o arroz através do aumento na disponibilidade de nutrientes, água e até a antecipação do processo de auto-calagem podem ter 
contribuído para este incremento na MS da parte área das plantas, que foi de $9 \%$ aos 48 DAE e de $15 \%$ aos 128 DAE. Nesse sentido, CASTILLO et al. (1992) consideram provável uma diminuição de produtividade de grãos e de produção de MS da parte aérea quando se suprime a irrigação entre os 15 e 35 DAE. DEL GIUDICE (1983) e BEYROUTY et al. (1994) também constataram que o maior fornecimento de água (irrigação por submersão durante todo o ciclo da cultura) aumenta a produção de MS e a absorção de nutrientes.

As análises de tecido realizadas nos estádios de perfilhamento, floração e na maturação, utilizando toda a parte aérea das plantas, demonstram que a absorção de nutrientes pelas plantas de arroz não foi influenciada pelos diferentes tratamentos com calcário. Estes resultados estão de acordo com LOPES et al. (1995), que relatam que a absorção de N, P, K, Ca e $\mathrm{Mg}$ não foi influenciada pelos tratamentos com calcário. Por outro lado, a época de início de irrigação influenciou a produção de MS da parte aérea das plantas de arroz, como também a quantidade de nutrientes absorvidos por estas plantas (Figura $1 \mathrm{e}$ Tabelas 2 e 3). Assim, a maior absorção de nutrientes no experimento com inicio da irrigação aos $15 \mathrm{DAE}$, deve-se à maior produção de MS, provavelmente devido a maior disponibilidade de nutrientes, obtido com a antecipação do início da irrigação (BEYROUTY et al., 1994).

A quantidade de $\mathrm{Al}^{+++}$absorvida pelas plantas não diferiu estatisticamente entre as épocas de início de irrigação, na avaliação realizada no perfillhamento (Tabela 2). Porém, em função da quantidade de MS da parte aérea produzida, o teor deste nutriente no tecido foi maior no experimento com início da irrigação aos $35 \mathrm{DAE}$ do que no experimento com início da irrigação aos $15 \mathrm{DAE}$ (Tabela 3 ). Isto pode indicar que o $\mathrm{Al}^{+++}$existente no solo foi menos absorvido no experimento com início da irrigação aos 15 DAE, provavelmente, por ter sido imobilizado mais cedo neste experimento, pelo efeito da calagem e/ou do alagamento. Entretanto, como não houve diferença entre tratamentos com calcário, o principal fator pode ser considerado a antecipação da irrigação.

A produção de MS das plantas de arroz (Figura 1) e o acúmulo dos nutrientes $\mathrm{N}, \mathrm{K}, \mathrm{Ca}$ e $\mathrm{Mg}$, na floração da cultura, foram semelhantes nos experimentos com início da irrigação aos 15 e aos 35 DAE (Tabela 2). Resultados seme
Tabela 2 - Acúmulo de nutrientes ( $\mathrm{kg} / \mathrm{ha}$ ) na parte aérea de plantas de arroz no perfilhamento e floração, com irrigação iniciada aos 15 e aos 35 dias após a emergência das plântulas (DAE). Santa Maria/RS, 1995/96.

\begin{tabular}{lrrrr}
\hline \multirow{2}{*}{$\begin{array}{l}\text { Nutriente } \\
\text { Mineral }\end{array}$} & \multicolumn{2}{c}{ Perfilhamento } & \multicolumn{2}{c}{ Floração } \\
\cline { 2 - 5 } & & & & \\
& $15 \mathrm{DAE}$ & $35 \mathrm{DAE}$ & $15 \mathrm{DAE}$ & $35 \mathrm{DAE}$ \\
& & & & \\
\hline & & & & \\
$\mathrm{N}$ & $57,92 \mathrm{a}$ & $37,28 \mathrm{~b}$ & $126,62 \mathrm{a}$ & $112,67 \mathrm{a}$ \\
$\mathrm{P}$ & $8,59 \mathrm{a}$ & $4,54 \mathrm{~b}$ & $17,92 \mathrm{a}$ & $14,30 \mathrm{~b}$ \\
$\mathrm{~K}$ & $166,10 \mathrm{a}$ & $109,68 \mathrm{~b}$ & $230,13 \mathrm{a}$ & $208,30 \mathrm{a}$ \\
$\mathrm{Ca}$ & $11,79 \mathrm{a}$ & $7,55 \mathrm{~b}$ & $18,21 \mathrm{a}$ & $17,97 \mathrm{a}$ \\
$\mathrm{Mg}$ & $15,88 \mathrm{a}$ & $11,84 \mathrm{~b}$ & $45,22 \mathrm{a}$ & $43,96 \mathrm{a}$ \\
$\mathrm{Al}$ & $3,31 \mathrm{a}$ & $3,24 \mathrm{a}$ & $2,79 \mathrm{~b}$ & $3,58 \mathrm{a}$ \\
$\mathrm{Mn}$ & $2,10 \mathrm{~b}$ & $2,62 \mathrm{a}$ & $3,29 \mathrm{~b}$ & $3,94 \mathrm{a}$ \\
& & & & \\
\hline
\end{tabular}

* Tratamentos com médias não seguidas de mesma letra, para cada nutriente e para as duas variáveis, diferem entre si em nivel de 5\% de significância pelo teste de Duncan.

lhantes foram obtidos por BEYROUTY0 et al. (1994) para os elementos $\mathrm{N}, \mathrm{K}$ e produção de $\mathrm{MS}$, quando comparavam épocas de início de irrigação.

Foi observada diferença signficativa no acúmulo dos nutrientes $\mathrm{P}, \mathrm{Al}^{+++}$e $\mathrm{Mn}$ no tecido das plantas desenvolvidas nos experimentos com início de irrigação aos 15 e aos 35 DAE, no estádio de floração (Tabela 2). Sendo que no florescimento das plantas, o

Tabela 3 - Quantidade de nutrientes absorvidos pela palha e grão das plantas de arroz na maturação ( $\mathrm{kg} / \mathrm{ha}$ ), nos experiemntos com início de irrigação aos 15 e aos 35 dias após a emergência das plântulas (DAE). Santa Maria/RS, 1996

\begin{tabular}{lrrrrrr}
\hline $\begin{array}{l}\text { Nutriente } \\
\text { Mineral }\end{array}$ & \multicolumn{3}{c}{ palha } & \multicolumn{2}{c}{ grãos } & palha+grãos \\
& & & & & & \\
& $15 \mathrm{DAE}$ & $35 \mathrm{DAE}$ & $15 \mathrm{DAE}$ & $35 \mathrm{DAE}$ & $15 \mathrm{DAE}$ & $35 \mathrm{DAE}$ \\
& & & & & & \\
\hline & & & & & & \\
$\mathrm{N}$ & $105,13 \mathrm{a}$ & $73,27 \mathrm{~b}$ & $84,56 \mathrm{a}$ & $72,86 \mathrm{~b}$ & $189,69 \mathrm{a}$ & $146,13 \mathrm{a}$ \\
$\mathrm{P}$ & $12,45 \mathrm{a}$ & $7,82 \mathrm{~b}$ & $10,90 \mathrm{a}$ & $9,92 \mathrm{~b}$ & $23,35 \mathrm{a}$ & $17,74 \mathrm{~b}$ \\
$\mathrm{~K}$ & $274,90 \mathrm{a}$ & $234,16 \mathrm{~b}$ & $23,10 \mathrm{a}$ & $24,08 \mathrm{a}$ & $298,00 \mathrm{a}$ & $258,24 \mathrm{a}$ \\
$\mathrm{Ca}$ & $29,50 \mathrm{a}$ & $25,70 \mathrm{a}$ & $3,08 \mathrm{a}$ & $2,95 \mathrm{a}$ & $32,58 \mathrm{a}$ & $28,65 \mathrm{a}$ \\
$\mathrm{Mg}$ & $22,42 \mathrm{a}$ & $16,84 \mathrm{~b}$ & $8,50 \mathrm{a}$ & $8,27 \mathrm{a}$ & $30,92 \mathrm{a}$ & $25,11 \mathrm{~b}$ \\
$\mathrm{Al}$ & $4,62 \mathrm{a}$ & $3,23 \mathrm{~b}$ & $0,40 \mathrm{a}$ & $0,40 \mathrm{a}$ & $5,02 \mathrm{a}$ & $3,63 \mathrm{~b}$ \\
$\mathrm{Mn}$ & $4,41 \mathrm{a}$ & $4,40 \mathrm{a}$ & $0,22 \mathrm{a}$ & $0,20 \mathrm{a}$ & $4,63 \mathrm{a}$ & $4,60 \mathrm{a}$ \\
& & & & & & \\
\hline
\end{tabular}

* Tratamentos com médias não seguidas de mesma letra, para cada nutriente e para cada variável, diferem entre si em nível de $5 \%$ de significância pelo teste de Duncan. 
$P$ foi mais absorvido no experimento com início da irrigação aos $15 \mathrm{DAE}$ e os nutrientes $\mathrm{Al}^{+++}$e $\mathrm{Mn}$ no experimento com início da irrigação aos 35 DAE indicando que os principais problemas da acidez do solo, $\mathrm{Al}^{+++}$e $\mathrm{Mn}$, permaneceram por um maior periodo no solo e foram assim absorvidos pelas plantas de arroz, podendo-se postular que nesta situação a autocalagem ocorreu mais tardiamente do que no experimento com início da irrigação aos $15 \mathrm{DAE}$.

No estádio de maturação os nutrientes $\mathrm{N}, \mathrm{K}$, $\mathrm{Ca}$ e $\mathrm{Mn}$, na palha + grãos, foram absorvidos em quantidades semelhantes nas duas épocas de início de irrigação. Mas, as quantidades de $\mathrm{P}, \mathrm{Mg} \mathrm{e} \mathrm{Al}^{+++}$ absorvidas pela parte aérea das plantas de arroz com início de irrigação aos 15 DAE foram significativamente superiores àquelas quantidades absorvidas pelas plantas com início de irrigação aos 35 DAE (Tabela 3). Essa maior absorção de nutrientes no experimento com início da irrigação aos 15 DAE pode ser atribuída a maior produção de MS (Figura 1). A quantidade de nutrientes absorvidos ao final do ciclo da cultura são semelhantes aos valores referidos por DE DATTA (1981), YOSHIDA (1981) e FAGERIA (1984). A maior absorção de $P$ no experimento com irrigação iniciada aos 15 DAE foi observada desde a primeira avaliação e possivelmente esteja relacionada com a maior disponibilidade de $\mathrm{P}$ no solo devido a antecipação da irrigação definitiva.

\section{CONCLUSÕES}

Antecipar o início da irrigação de 35 para 15 dias após a emergência das plântulas de arroz proporciona maior absorção de nutrientes e maior produção de massa seca na parte aérea das plantas de arroz.

A calagem parcial ou total recomendada pelas análises do solo não afeta a absorção de nutrientes nem a produção de massa seca na parte aérea das plantas de arroz irrigado.

\section{REFERÊNCIAS BIBLIOGRÁFICAS}

BEYRCUTY, C.A., GRIGG, R.J., NORMAN, R.L., et al. Nutrient uptake by rice in response to water management. Journal of Plant Nutrition. New York, v. 17, n. 1, p. 39-55 1994.

CASTILLO, E.G., BURESH, R., INGRAM, T.K. Lowland rice yield affected by timing of water deficit and nitrogen fertilization. Agronomy Journal, Madison, v. 84, p. 152-159. 1992

DE DAT'TA. S.K. Principles and practices of rice production. New York: John Wiley \& Sons, 1981.618 p.

DEL GIUDICE, M. Absorção cumulativa de nutrientes minerais em duas variedades de arroz (Oryza sativa $L$.) cultivados em três diferentes níveis de disponibilidade de água. Campinas: Fundação Cargil, 1983.110 p.
FAGERIA, N.K., ZIMMERMANN, F.L.P., LOPES, A.M. Resposta do arroz irrigado à aplicação de fósforo, zinco e calcário. Revista Brasileira de Ciência do Solo, Campinas, v. 1, p. 72 76, 1977.

FAGERIA, N.K. Adubação e nutrição mineral da cultura de arroz. Rio de Janciro: EMBRAPA - CNPAF, 1984. 341 p.

FOY, C.D. Effects of aluminium on plant growth. In. THE PLANT ROOT AND ITS ENVIRONMENT, 1974, Anais... Charlottesville: University Press of Virginia, 1974, p. 601-642.

FOY, C.D. Physiological effects of hidrogen, aluminium, and manganese toxicities in acid soil. In: SOIL ACIDITY AND LIMING. 2. 1984, Madison. Proceedings... Madison: Amcrican Society of Agronomy,: Crop Science Society of America: Soil Science Society of America, 1984. 380 p. p. 57-86.

GOMES, A.S., VHAL, L.C., TURATTI, A.L. et al. Início de irrigação x supressão de água à lavoura de arroz irrigado. In: REUNIÃO DA CULTURA DO ARROZ IRRIGADO, $11,1981$. Pelotas. Anais... Pelotas:EMBRAPA/CPACTB, 1981 p. 203206.

GOMES. A.S., VHAL. L.C. TURATTI, A.L. et al. F́pocas de inicio e término da inundação do solo para cultivares de porte baixo no Rio Grande do Sul. In: REUNIÃO NACIONAL. DE: PESQUISA DE ARROZ, 3., 1987, Goiânia. Resumos... Goiânia: EMBRAPA/CNPAF, 1987. 132 p. p. 37.

KAMINSKI, J.A acidez dos solos e a fisiologia das plantas. In: SEMINÁRIO SOBRE CORRETIVOS DA ACIDEZ DO SOLO. 2, 1989, Santa Maria. Anais... Santa Maria: UFSM. 1989. 224 p. p. 39-61.

LEFROY, R.D.B., SAMOSIR, S.S.R., BLAIR, G.J. The dynamics of sulfur, phosphorus and iron in flooded soils as affected by changes in Eh and $\mathrm{pH}$. Australian Journal of Soil Research. Sidney, v. 33, p. 493-508, 1993.

LOPES, S.I.G., LOPES, M.S., MACEDO, V.R.M. Resposta da cultura do arroz irrigado à aplicação de calcário. In: REUNIX̃O DA CULTURA DO ARROZ IRRIGADO, 21. 1995. Porto Alegre. Anais... Porto Alegre. IRGA. 1995. 333 p. p. 169-171.

LOPES, S.I.G. Recomendação de adubação e calagem para a cultura do arroz irrigado no Estado do Rio Grande do Sul. In: CURSO DE ATUALIZAÇÃO EM RECOMENDAÇÃO DE ADUBAÇÃO E CALAGEM, 2., 1996, Santa Maria Resumos... Santa Maria: Departamento de Solos. UFSM, 1996. 68 p. p. $64-68$

PATRA. B.N.. MOHANTY, S.K. Efect of nutrients and liming on changes in $\mathrm{pH}$, redox potential, and uptake of iron and manganese by wetland rice in iron-toxic soil. Biology and Fertility of Soils, Berlin, v. 17, p. 255-258,1994.

SOCIEDADE BRASILEIRA DE CIÊNCIA DO SOLO. Comissão de Fertilidade do Solo do RS/SC. Recomendações de adubaça e calagem para os Estados do Rio Grande do Sul e de Santa Catarina. 3. ed. Passo Fundo: SBCS, Núcleo Regional Sul. 1994. $224 \mathrm{p}$.

TEDESCO, M.L., GIANELLO, C., BISSANI, C.A. et al. Análises de solo, plantas e outros materiais. 2 ed. Porto Alegre: UFRGS, Faculdade de Agronomia, Departamento de Solos. 1995. 174 p. (Boletim técnico de solos. 5).

YOSHIDA, S. Fundamentals of rice crop science. Los Baños: International Rice Research Institute, 1981.269 p. 